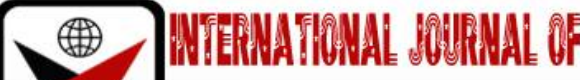

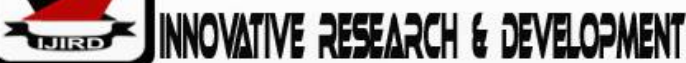

ISSN 2278 - 0211 (Online)

\section{The Predictive Validity of Mathematics and English Literature on Year One and Two Law Courses in Delta State University, Abraka, Nigeria}

\author{
Dr. Orifamah Daniel \\ Lecturer, Department of Physical Science Education, IMO State University, Owerri, Nigeria
}

\begin{abstract}
:
Among the many professions in the world is the legal profession that has been from ancient times been classified as a "noble profession" that not being enough it is presently referred to as a "learned profession" and members call themselves "learned friends" a term that tends to connote epitome of knowledge. That being so, the investigator set out to study the "predictive validity of some of their entry requirement subjects (Mathematics and English Literature) on law courses during the first two years of study using Delta State University Abraka (Oleh Campus) for the investigation. The aim was to establish the relationship between Mathematics and English literature and their performance in the first two years of entry (admission). Data collection was done based on the records available at the Delta State University Abraka. Six research questions and six hypotheses were formulated and answered using Pearson Product Moment Correlation Coefficient ( $r$ ). the standardized regression coefficients Beta or $\beta$ 'showing 95.0\% confidence interval with an upper and lower bound for the six predictors were checked. The result of this study showed that Mathematics and English literature as a prerequisite subjects for admission into the faculty of law in Delta State University has a negative relationship with Cumulative Grade Point Average (CGPA). With the six null hypothesis accepted and with the coefficients having the 95\% confidence interval for Beta showing lower and upper bounds all cutting across zero.
\end{abstract}

Keywords: Profession, legal profession, noble profession, learned profession, learned friend, validity, archival, expose facto

\section{Introduction}

One of the many definitions of a profession is: a vocation founded upon specialized educational training.......... (en.wikipedia.org/wiki/profession). And the most important aspect of any educational training is validity. Validity refers to any psychological attributes: cognitive, affective, psychomotor and psycho productive. Therefore, validity is an all important aspect in any educational training or central concept to psychologist and especially to the instrumental researchers.

Validity as a psychological concept cannot just like any other concept be pinned down to one acceptable definition. Some of the definitions are:

"What a test measure and how well it does to" Amastasi (2007:1270). "The degree with which the influences based on test scores are meaningful, useful and appropriate" Bruandi (1999). "The extent to which a test of any psychological attribute actually and adequately measures what it purports to measure and nothing else" Kpolovie (2010). "The extent to which a test measures what it is suppose to measure". Henry Gleitman, Alan J. Fridlund, Daniel Reisbery (2003:557) and to the researcher validity is the ability of any instrument to measure accurately an expected latent trait.

There are many phases if validity - these are content, construct and criterion (Concurrent/predictive). Some Authors introduced a fourth sort of validity called face validity. Face validity "is not validity in procedural sense. It denotes the suitability of the test relative to the course on which the test is founded" Ukozor (2016:187) "what people reflect as face validity is strictly or psychologically neither a type of validity nor a way of instituting validity because it does not essentially refers to what a test measures" Kpolovie (2010:520).

Now, right from the ancient times certain professions like medicine and law have been regarded as noble profession. That not being enough, the law profession is presently called and referred to as a "learned profession" and members of the profession be they Barrister or Solicitors (lawyers) called themselves as "learned friends". By this title it seems as through the law profession is the only valid profession in terms of education.

The classification of any profession should be based on validity, and validity is based on tests on the cognitive, affective, psychomotor and the psycho productive domains, which should reflect the content, construct and criterion (predictive/concurrent) related validity aspects of the said profession. The purpose of this research work therefore is to find out the predictive validity of English Literature and Mathematics on Year 1 and Year 2 law students in Delta State University, Abraka. 
In order to achieve the purpose of this study six research questions and six hypotheses were formulated, answered and tested respectively.

\section{Research Questions}

- What is the relationship between the 2012/13 law students O/L Mathematics performance and CGPA in year one?

- What is the relationship between the 2012/13 law students O/L English Literature performance and CGPA in year one?

- What is the relationship between the 2012/13 law students O/L Mathematics and English Literature combined performance and their CGPA in year one?

- What is the relationship between the 2012/13 law students O/L Mathematics performance and CGPA in year two?

- What is the relationship between the 2012/13 law students' O/L English Literature performance and CGPA in year two?

- What is the relationship between the 2012/13 law students' Mathematics and English Literature combined and the CGPA in year two?

\subsection{Hypotheses}

- There is no significant relationship between the 2012/13 law students' O/L Mathematics performance and their CGPA in year one $(\mathrm{P}<0.05)$.

- There is no significant relationship between the 2012/13 law students' O/L English Literature performance and their CGPA in year one $(\mathrm{P}<0.05)$.

- There is no significant relationship between the 2012/13 law students' O/L Mathematics and English Literature combined and their CGPA in year one $(\mathrm{P}<0.05)$.

- There is no significant relationship between the 2012/13 law students' O/L Mathematics performance and their CGPA in year two $(\mathrm{P}<0.05)$.

- There is no significant relationship between the 2012/13 law students' O/L English Literature performance and their CGPA in year two $(\mathrm{P}<0.05)$.

- There is no significant relationship between the 2012/13 law students' O/L Mathematics and English Literature combined performance and their CGPA in year two $(\mathrm{P}<0.05)$.

2.2. Note

CGPA = Cumulative grade point average

$\mathrm{O} / \mathrm{L} \quad=$ Ordinary level result

\section{Method}

\subsection{Design/Instrumentation}

The study is archival expose facto correlation research design. Data on O/L result were collected from the students' Affairs Office and the CGPA of the students collected from Examination and Records Office of Delta State University, Abraka (Oleh Campus). Authority to release same for research purpose was gotten through the Provost and the faculty Dean to the respective offices. The collected data were used to answer the research questions and test the hypotheses by correlating the predictors on the criterions using regression statistics.

\subsection{Population of Study}

The study was carried out in Delta State University, Abraka - Oleh Campus, the population was all the law students in the school and the target population was all the Year one students 2012/13 academic section and who were able to complete the first and second academic year. They were sixty-eight students (68) in number.

\section{Data Analysis and Result}

\begin{tabular}{|c|c|c|c|c|c|}
\hline \multicolumn{2}{|c|}{ CORRELATIONS } & \multicolumn{4}{|c|}{ CHANGE STATISTICS (R) } \\
\hline Yr1M & Yr1E & Yr1ME & R & $\mathrm{R}^{2}$ & $\mathrm{~F}$ \\
\hline 0.313 & 0.115 & 0.246 & 0.316 & 0.100 & 2.365 \\
\hline
\end{tabular}

Table 1: Regression Table Showing CGPA of Year One with Mathematic (Yr1M), with

Literature in English (Yr1E) and with Mathematics and English Literature Combined (Yr1ME)

\begin{tabular}{|c|c|c|c|c|c|}
\hline \multicolumn{2}{|c|}{ CORRELATIONS } & \multicolumn{4}{|c|}{ CHANGE STATISTICS (R) } \\
\hline Yr2M & Yr2E & Yr2ME & R & $\mathrm{R}^{2}$ & $\mathrm{~F}$ \\
\hline 0.382 & 0.139 & 0.299 & 0.148 & 0.022 & 3.706 \\
\hline
\end{tabular}

Table 2: Regression Table Showing CGPA of Year Two with Mathematic (Yr2M), with

Literature in English (Yr2E) and with Mathematics and English Literature Combined (Yr2ME) 


\begin{tabular}{|c|c|c|c|c|c|}
\hline Var. 2 & Var. 3 & Var. 4 & Var. 6 & Var. 7 & Var. 8 \\
\hline 0.342 & -0.148 & 0.291 & 0.403 & -0.179 & -0.348 \\
\hline
\end{tabular}

Table 3: Standardized Multiple Regression Table for the Two Years

\begin{tabular}{|c|c|c|c|c|c|}
\hline Var. 2 & Var. 3 & Var. 4 & Var. 6 & Var. 7 & Var. 8 \\
\hline 0.222 & -0.113 & 0.175 & 0.270 & -0.140 & 0.216 \\
\hline
\end{tabular}

Table 4: Standardized Regression Coefficients (Beta or B) for the 2 Yrs

\begin{tabular}{|c|c|c|c|c|c|}
\hline Var. 2 & Var. 3 & Var. 4 & Var. 6 & Var. 7 & Var. 8 \\
\hline-0.583 to & -1.132 to & -1471 to & -0.471 to & -1.108 to & -1.317 to \\
\hline 1.257 & 0.835 & 2.053 & 1.277 & 0.750 & 2.013 \\
\hline
\end{tabular}

Table 5: Table Showing 95\% Confidence Intervals for the Contribution of Each Variable into the Prediction

NOTE:

Var. $1=$ CGPA (Cumulative Grade Point Average) for year 1

Var. $2=$ O/L Mathematics Scores, Var. 3 = 0/L English Literature scores

Var. $4=$ O/L Mathematics/English Literature scores, Var. 5 = CGPA for year 2

Var. $6=$ O.L Mathematics scores, Var. $7=0 /$ Lnglish Literature scores

Var. $8=0 /$ L Mathematics/English Literature Scores

$\mathrm{O} / \mathrm{L}=$ Ordinary level

NECO, = National Examination Council

WAEC $=$ West African Examination Council

Note also that NECO and WAEC are given equal weight (rated as same)

\subsection{Analysis Concerning Research Questions and Hypotheses}

- RQ1: What is the relationship between the 2012/13 law students O/L Mathematics performance and CGPA in year one.

- H01: There is no significant relationship between the 2012/13 law students' O/L Mathematics performance and their CGPA in year one $(\mathrm{P}<0.05)$.

The table 1, shows a correlation of $0 / \mathrm{L}$ Mathematics performance with CGPA in year one to be 0.313 , significant at (P > 0.05), as seen from Yr1M in table 1. A change statistics or model summary $\left(R^{2}\right)$ of 0.100 which means that the Mathematics performance as a predictor in the year one account for only $10 \%$ of the variance in the year one Cumulative Grade Point Average (CGPA) which is the criterion for the first year. The standardized multiple regression in table 3, var.2 is 0.342 while the Standardized regression coefficients (Beta or $\beta$ ) that are actually tested for significance in table 4 , Var. 2 is 0.222 , significant at $(\mathrm{P}>0.05)$. Var. 2 in table 5, showed 95\% confidence interval for the contribution of variable two (var. 2) into the prediction which ranges from -0.583 to 1.257 , an indication of no significance. Statistically, for any variable that has the confidence interval range which cuts across zero, the contribution of the variable to the prediction of the criterion are not statistically significant. Kpolovie (2010).

Conclusively, it can be seen from the above that the hypothesis which states that: "There is no significant relationship between the 2012/13 law students' 0/L Mathematics performance and their CGPA in year one $(\mathrm{P}<0.05)$." is accepted.

- RQ2: What is the relationship between the 2012/13 law students 0/L English Literature performance and CGPA in year one.

- HO2: There is no significant relationship between the 2012/13 law students' O/L English Literature performance and their CGPA in year one $(\mathrm{P}<0.05)$.

The table 1, shows a correlation of O/L English Literature performance with CGPA in year one to be 0.115 , significant at $(\mathrm{P}>0.05)$, as seen from Yr2M in table 1 . A change statistics $\left(R^{2}\right)$ of 0.100 which means that the Mathematics performance as a predictor in the year one account for only $10 \%$ of the variance in the year one Cumulative Grade Point Average (CGPA) which is the criterion for the first year. The standardized multiple regression in table 3 , var.3 is

0.148 while the standardized regression coefficients (Beta or $\beta$ ) that are actually tested for significance in table 4 , Var. 3 is 0.113 , significant at $(\mathrm{P}>0.05)$. Var. 3 in table 5 , showed $95 \%$ confidence interval for the contribution of variable three (var. 3) into the prediction which ranges from -1.132 to 0.835 , an indication of no significance.

Conclusively, it can be seen from the above that the hypothesis which states that: "There is no significant relationship between the 2012/13 law students' O/L English Literature performance and their CGPA in year one (P<0.05)." is accepted.

- RQ3: What is the relationship between the 2012/13 law students O/L Mathematics and English Literature combined performance and their CGPA in year one.

- H03: There is no significant relationship between the 2012/13 law students' O/L English Literature performance and their CGPA in year one $(\mathrm{P}<0.05)$. 
The table 1, shows a correlation of O/L English Literature performance with CGPA in year one to be 0.246 , significant at $(\mathrm{P}>0.05)$, as seen from Yr1ME in table 1. A change statistics $\left(R^{2}\right)$ of 0.100 which means that the Mathematics and English Literature combined performance and their CGPA in year one as a predictor in the year one account for only $10 \%$ of the variance in the year one Cumulative Grade Point Average (CGPA) which is the criterion for the first year. The standardized multiple regression in table 3, var.4 is 0.291 while the Standardized regression coefficients (Beta or $\beta$ ) that are actually tested for significance in table 4 , Var. 4 is 0.175 , significant at $(\mathrm{P}>0.05)$. Var. 4 in table 5 , showed $95 \%$ confidence interval for the contribution of variable four (var. 4) into the prediction which ranges from - 0.471 to 2.053 , an indication of no significance.

Conclusively, it can be seen from the above that the hypothesis which states that:

“There is no significant relationship between the 2012/13 law students' O/L English Literature performance and their CGPA in year one $(\mathrm{P}<0.05)$." is accepted.

- RQ4: What is the relationship between the 2012/13 law students O/L Mathematics performance and CGPA in year two.

- HO4: There is no significant relationship between the 2012/13 law students' O/L Mathematics performance and their CGPA in year two $(\mathrm{P}<0.05)$.

The table 2, shows a correlation of O/L Mathematics performance with CGPA in year two to be 0.382 , significant at (P $>0.05)$, as seen from Yr2M in table 2. A change statistics $\left(R^{2}\right)$ of 0.022 which means that the Mathematics performance as a predictor in the year two account for only $02 \%$ of the variance in the year two Cumulative Grade Point Average (CGPA) which is the criterion for the second year. The standardized multiple regression in table 3, var.6 is 0.403 while the Standardized regression coefficients (Beta or $\beta$ ) that are actually tested for significance in table 4, Var. 6 is 0.270 , significant at ( $\mathrm{P}>0.05)$. Var. 6 in table 5, showed 95\% confidence interval for the contribution of variable six (var. 6) into the prediction which ranges from -0.471 to 1.277 .

Conclusively, it can be seen from the above that the hypothesis which states that: "There is no significant relationship between the 2012/13 law students' 0/L Mathematics performance and their CGPA in year two ( $<<0.05)$." is accepted.

- RQ 5: What is the relationship between the 2012/13 law students O/L English Literature performance and CGPA in year two

- HO 5: There is no significant relationship between the 2012/13 law students' O/L English Literature performance and their CGPA in year two $(\mathrm{P}<0.05)$.

The table 2, shows a correlation of O/L English Literature performance with CGPA in year two to be 0.139 , significant at (P $>0.05$ ), as seen from Yr2M in table 2. A change statistics $\left(R^{2}\right)$ of 0.022 which means that the Mathematics performance as a predictor in the year two account for only $02 \%$ of the variance in the year two Cumulative Grade Point Average (CGPA) which is the criterion for the first year. The standardized multiple regression in table 3 , var.7 is -0.179 while the Standardized regression coefficients (Beta or $\beta$ ) that are actually tested for significance in table 4, Var. 7 is -0.140 , significant at $(\mathrm{P}>0.05)$. Var. 7 in table 5, showed 95\% confidence interval for the contribution of variable three (var.7) into the prediction which ranges from -1.108 to 0.750 , an indication of no significance.

Conclusively, it can be seen from the above that the hypothesis which states that: "There is no significant relationship between the 2012/13 law students' O/L English Literature performance and their CGPA in year two ( $<<0.05)$." is accepted.

- RQ6: What is the relationship between the 2012/13 law students O/L Mathematics and English Literature combined performance and their CGPA in year two.

- HO6: There is no significant relationship between the 2012/13 law students' O/L Mathematics and English Literature combined performance and their CGPA in year two $(\mathrm{P}<0.05)$.

The table 2, shows a correlation of O/L English Literature performance with CGPA in year two to be 0.299 , significant at (P $>0.05$ ), as seen from Yr2ME in table 2. A change statistics $\left(R^{2}\right)$ of 0.022 which means that the Mathematics and English Literature combined performance and their CGPA in year two as a predictor in the year two account for only $02 \%$ of the variance in the year one Cumulative Grade Point Average (CGPA) which is the criterion for the second year. The standardized multiple regression in table 3, var.8 is -0.348 while the Standardized regression coefficients (Beta or $\beta$ ) that are actually tested for significance in table 4 , Var. 8 is 0.216, significant at $(\mathrm{P}>0.05)$. Var. 8 in table 5, showed 95\% confidence interval for the contribution of variable eight (var. 8) into the prediction which ranges from -1.317 to 2.013 , an indication of no significance.

Conclusively, it can be seen from the above that the hypothesis which states that:

“There is no significant relationship between the 2012/13 law students' O/L English Literature performance and their CGPA in year two $(\mathrm{P}<0.05)$." is accepted.

\section{Conclusion}

In conclusion, the investigator has pypainstakingly examined the predictive validity of Mathematics and English Literature on year 1 and year 2 law courses which are the two major prerequisites for admission into the faculty of law in Delta State University, Abraka. And the result clearly showed lack of validity which means the use of Mathematics and English Literature as a criterion for admission have no validity. Therefore the investigator recommend that other subjects be chosen as prerequisites for admission into the faculty of law. 


\section{References}

i. Anastasi, A. and Urbina, S., (2007). Psychologist Testing (7th ed); India: Dorling Kindersly.

ii. Brualdi, A. (1999). Traditional and Modern Concept of Validity. www.eric/aeDigest Eric Identifier. ED 435714.

iii. Freedman, D. A. (2009). Freedman, Statistics Theory and Practice, (revised ed.). Cambridge University Press.

iv. Henry, G., Alan, J.F., and Daniel R. (2003). Psychology: (6 $6^{\text {th }}$ ed) USA: www.norton and company.

v. https://www.statisticshowto.datasciencecentral.com. What is a Standardized Beta Coefficient?

vi. https://www.thelawyerportal,com .Difference between a barrister and a solicitor

vii. Kpolovie, P.J. (2010). Advanced Research Methods: Owerri, Springfield Publishers Ltd.

viii. Ukozor, F.I. (2016). Measurement and Evaluation: A Comprehensive Test for Students and Teachers: Owerri, Flashpointz.

ix. www.en.wikipedia.org/wiki/professio n: what is a profession?

x. www.en.wikipedia.org/wiki Confidence interval. 